\title{
Indicadores biofísicos de degradação ambiental da Bacia Hidrográfica do rio Piracuruca
}

\section{Biophysical indicators of environmental degradation in the Piracuruca Hydrographic Basin}

\author{
Francílio de Amorim dos Santos \\ Doutor em Geografia. Docente do Instituto Federal do Piaú / Campus Piripiri, Brasil \\ francilio.amorim@ifpi.edu.br
}

\begin{abstract}
Resumo
A pesquisa analisar o estado de conservação/degradação ambiental das unidades de paisagem da Bacia Hidrográfica do rio Piracuruca, a partir da integração dos indicadores biofísicos litologia, declividade média do relevo, erosividade das chuvas, erodibilidade dos solos e índice de cobertura vegetal ajustado ao solo. O estudo diz é uma pesquisa aplicada, explicativa e empregou estatística para quantificação dos dados das componentes ambientais e construção do índice de degradação biofísica. Foram mapeadas as seguintes unidades de paisagem: platô do Planalto da Ibiapaba, rebordos erosivos parcialmente dissercados do Planalto da Ibiapaba, rebordos erosivos moderadamente dissercados do Planalto da Ibiapaba, rebordos erosivos fortemente dissercados do Planalto da Ibiapaba, depressão monoclinal dissecada, depressão aplainada conservada, interflúvios tabulares, morros e colinas, fundos de vales associados à área de inundação, planícies fluviais. Os resultados apontaram que predomina na Bacia: rochas com baixa resistência, em 58,8\%; relevo plano, em 58,4\%; aridez alta, que ocorre por 59\%; erosividade das chuvas moderada, em 60,7\%; erodibilidade dos solos muito alta, frequente em 59,8\%; vegetação com baixa atividade fotossintética, distribuída por $49 \%$. A análise estatística demonstrou que: o IBFD4 obteve a menor variância, com 0,2; o IBFD5 aquele que exibiu a maior variância, com 1,7; o IBFD5 apresentou o maior desvio padrão, com 1,3; enquanto o IBFD5 indicou maior dispersão, com coeficiente de variação de $73,1 \%$. Por meio do índice de degradação foi possível reconhecer que a depressão aplainada conservada e o platô do Planalto da Ibiapaba apresentam baixa degradação ambiental, enquanto as demais unidades possuem degradação ambiental média.
\end{abstract}

Palavras-chave: Nordeste do Brasil; Bacia Hidrográfica; Sistemas ambientais; SIG; Álgebra de mapas.

\begin{abstract}
The research analyzes the state of conservation/environmental degradation of the landscape units of the Piracuruca River Basin from the integration of the biophysical lithology indicators, the average slope of the relief, rainfall erosivity, soil erodibility and vegetal coverage index adjusted to the soil. The study says it is an applied, explanatory research and used statistics to quantify the data of the environmental components and construction of the biophysical degradation index. The following landscape units were mapped: Ibiapaba Plateau, partially dissected erosive edges of the Ibiapaba Plateau, moderately dissolved erosive edges of the Ibiapaba Plateau, heavily dissolved erosive edges of the Ibiapaba Plateau, dissected monoclinal depression, conserved flattened depression, interfluvial tabular, hills and hills, valley bottoms associated with the flood area, river plains. The results showed that there is a predominance in the Basin: rocks with low resistance, in $58.8 \%$; flat relief, in $58.4 \%$; high aridity, which occurs by $59 \%$; moderate rainfall erosivity, at $60.7 \%$; very high soil erodibility, frequent in $59.8 \%$; vegetation with low photosynthetic activity, distributed by $49 \%$. The statistical analysis showed that: IBFD4 obtained the smallest variance, with 0.2 ; the IBFD5 showed the highest variance, with 1.7; IBFD5 presented the largest standard deviation, with 1.3; while the IBFD5 indicated greater dispersion, with a coefficient of variation of $73.1 \%$. Through the
\end{abstract}


degradation index, it was possible to recognize that the conserved flattened depression and the plateau of the Ibiapaba Plateau show low environmental degradation. At the same time, the other units have average environmental degradation.

Keywords: Northeast of Brazil; Hydrographic Basin; Environmental Systems; GIS; Map Algebra.

\section{INTRODUÇÃO}

As paisagens naturais vêm sofrendo diversos impactos, ao longo da história humana, muitos deles irreversíveis. No Nordeste do Brasil distintas paisagens foram alteradas para ceder lugar a cidades, agropecuária, etc. Componentes ambientais, como relevo, solos, canais fluviais e, principalmente, a vegetação, vão sendo modificados para atender a demandas econômicas.

Dentre esses componentes ambientais, destaca-se a bacia hidrografia, considerada unidade básica para planejamento ambiental e, de acordo com Cazula e Mirandola (2010), compreende elementos que atuam de modo interdependente e harmônico, sendo cada componente fruto das mudanças externas impostas a eles.

Desse modo, a bacia configura-se como recorte espacial que tem sido bastante utilizado em pesquisa de cunho ambiental, pois permite integrar diversos elementos da paisagem, possibilitando a realização de diagnósticos acerca das condições de conservação e/ou degradação dos elementos que a compõe.

O espaço geográfico apresenta situações de intensa troca de energia e de matéria, cuja composição compreende um conjunto de componentes do ambiente natural nos seus três estados físicos (ROSS, 2010). Dessa forma, deve-se situar o conceito de sistemas no âmbito da Geografia, como possibilidade teórico-metodológica para estudos ambientais.

Camargo (2012, p.34) define o sistema como “[...] um elemento que, em virtude de sua interação interna e externa (com outros sistemas), evolui diacronicamente". Neves et al., (2014), por sua vez, apontam que a organização do sistema baseia-se nas inter-relações entre unidades, gerando um todo mais complexo que a soma das partes.

Nesse sentido, compreende-se o sistema como uma combinação de vários elementos, que são interdependentes e as mudanças ocorridas são dialéticas, onde cada subsistema tem influência sobre o outro e, como tal, repercussões no todo. Esses elementos, presentes nos sistemas, configuram possibilidades para usos dos recursos naturais, contudo esses usos devem considerar o potencial de cada espaço geográfico, particularmente a capacidade de regeneração do ambiente.

Florenzano (2005) ressalta que devido à escassez de recursos associada à extensão do território brasileiro resultam na possibilidade de usos das geotecnologias como meio alternativo para execução de pesquisas. Ao passo que o geoprocessamento tem-se tornado uma poderosa ferramenta para subsidiar estudos integrados da paisagem. Santos e Weber (2013) destacam a 
potencialidade do Geoprocessamento, como possibilidade para confecção dos produtos cartográficos e estes permitem analisar o objeto de estudo, de tal modo que ele pode ser interdisciplinar, posto que combine diversos saberes sobre um mesmo trabalho.

Nesse cenário, inserem-se os indicadores biofísicos, que compreendem um conjunto de variáveis de cunho ambiental que podem ser integradas por meio do uso de Sistemas de Informação Geográfica (SIG). Esses indicadores possibilitam estimar a dinâmica ambiental e sua integração gera a perspectiva para identificação de áreas com potencial para usos e àquelas com limitações advindas das características naturais do ambiente.

Diversos estudos têm se utilizado de indicadores para estudos ambientais, dentre esses se citam os seguintes: Oliveira (2011) realizou estudo realizado na Ilha de Santiago, Cabo Verde/África, para conhecer a dinâmica e o estado de degradação em que se encontram os sistemas ambientais, por meio do uso de sete indicadores biofísicos de desertificação; Aquino e Oliveira (2012), que se utilizaram de indicadores biofísicos para avaliar o processo de desertificação no Núcleo de São Raimundo Nonato (PI); Teixeira et al., (2018) empregaram algoritmos para monitoramento de parâmetros hídricos e de vegetação ao longo dos anos no Submédio São Francisco associado a parâmetros obtidos por sensoriamento remoto e de uma rede de estações climáticas envolvendo o período de 2003 a 2017.

Nesse contexto, o estudo buscou analisar o estado de conservação/degradação ambiental das unidades de paisagem da Bacia Hidrográfica do rio Piracuruca, a partir da integração dos indicadores biofísicos litologia, declividade média do relevo, erosividade das chuvas, erodibilidade dos solos e índice de cobertura vegetal ajustado ao solo.

\section{A ÁREA EM ESTUDO}

O estudo teve como recorte espacial a Bacia Hidrográfica do rio Piracuruca (BHRP), situada no semiárido brasileiro, particularmente na divisa dos estados do Ceará e do Piauí, norte da região Nordeste do Brasil. A Bacia compreende uma área de $7.704 \mathrm{~km}^{2}$, cujas principais nascentes ocorrem na Serra da Ibiapaba, município de São Benedito (CE), e na Serra dos Matões, município de Pedro II (PI). A Bacia drena áreas de 20 municípios, sendo 11 desses localizados em território piauiense e 9 no estado do Ceará (Figura 1). 


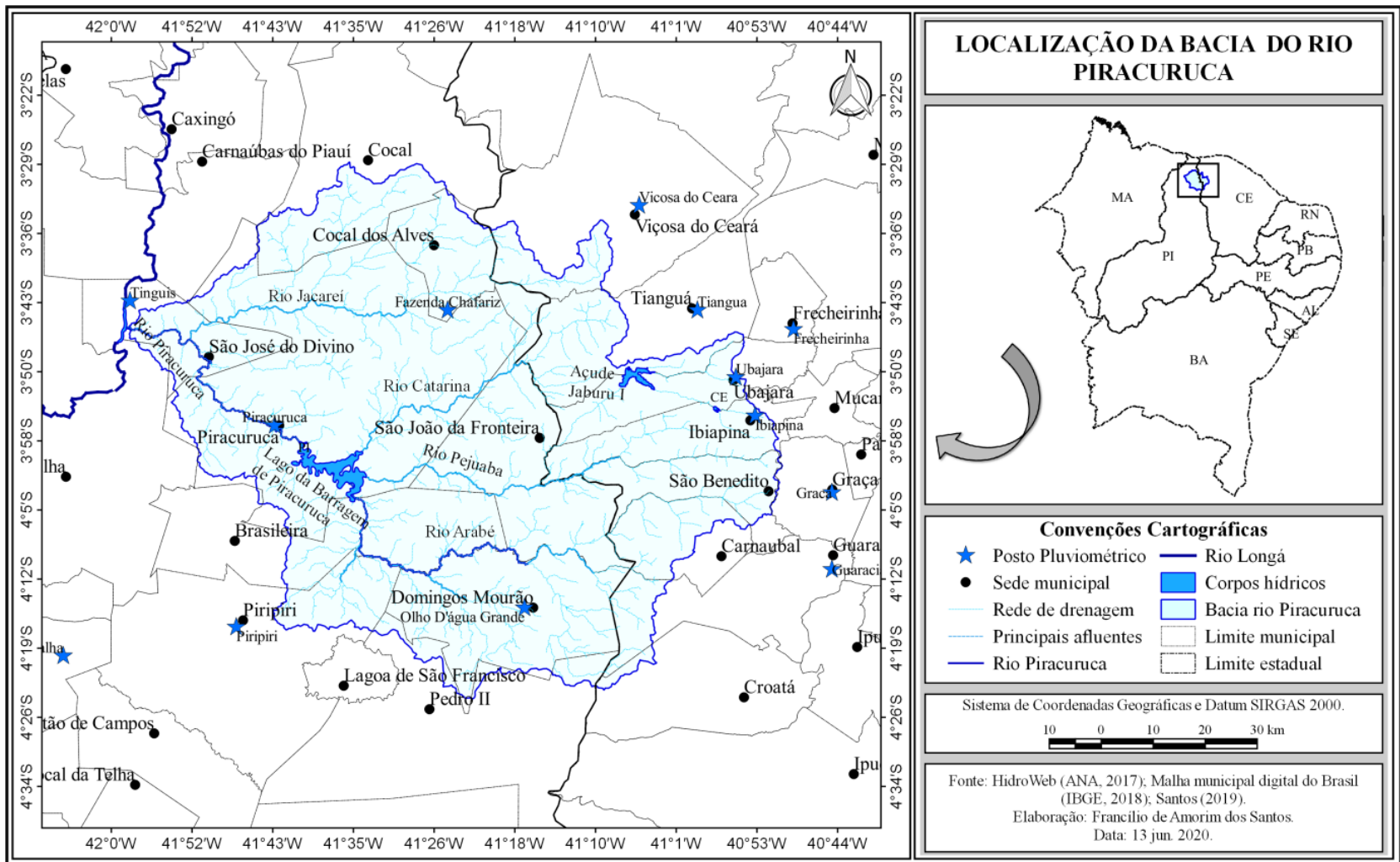

Figura 1 - Localização da Bacia Hidrográfica do rio Piracuruca, situada na divisa dos estados do Ceará e do Piauí, Nordeste do Brasil.

Fonte: ANA, (2017); IBGE (2018); Santos (2019).

A BHRP está localizada em área de litologia sedimentar, onde são encontradas as seguintes formações geológicas: Serra Grande, Pimenteiras, Cabeças, Longá, Sardinha e Depósitos ColúvioEluviais (Tabela 1). A principal forma de relevo encontrada na área é o Planalto da Ibiapaba, que apresenta topo plano, vertentes íngremes com marcas de festonamento, fruto da dissecação oriunda da rede de drenagem consequente, e altitudes que ultrapassam os $900 \mathrm{~m}$ de altitude.

Tabela 1: Características geológicas da Bacia Hidrográfica do rio Piracuruca.

\begin{tabular}{|c|c|c|c|c|}
\hline Era & Período & Formação & Litologia & $\%$ \\
\hline Cenozoica & Neógeno & $\begin{array}{l}\text { Depósitos Colúvio- } \\
\text { Eluviais }\end{array}$ & $\begin{array}{c}\text { Sedimentos arenosos, areno-argilosos e } \\
\text { conglomeráticos. }\end{array}$ & 12,6 \\
\hline \multirow[t]{3}{*}{ Mesozoico } & Cretáceo & Sardinha & Basaltos e diabásios. & 4,9 \\
\hline & & Longá & Folhelhos e arenitos. & 0,1 \\
\hline & Devoniano & Cabeças & Arenitos e siltitos. & 21,8 \\
\hline \multirow[t]{2}{*}{ Paleozoica } & & Pimenteiras & $\begin{array}{l}\text { Folhelhos com intercalações de arenitos e } \\
\text { siltitos. }\end{array}$ & 23,6 \\
\hline & Siluriano & Grupo Serra Grande & $\begin{array}{l}\text { Conglomerados, arenitos e intercalações } \\
\text { de siltitos e folhelhos. }\end{array}$ & 37,0 \\
\hline
\end{tabular}

Fonte: BRASIL (1973); CPRM (2006a; 2006b); PFALTZGRAFF, TORRES e BRANDÃO (2010). 
A Bacia do rio Piracuruca é classificada, de acordo com a proposta de Strahler (1952), como sendo de $6^{\text {a }}$ ordem (SANTOS, 2019). Essa Bacia está sob a influência da Zona de Convergência Intertropical (ZCIT), principal sistema provedor de chuvas, cujo posicionamento está associado aos fenômenos oceânicos El Niño Oscilação Sul (ENOS) e Dipolo do Atlântico, que atuando concomitante ou isoladamente cooperam para a ocorrência de anomalias pluviométricas interanuais, que resultam em secas ou inundações.

Foram identificadas onze subordens de solos (INDE, 2014), a saber: Argissolo Amarelo, Argissolo Vermelho, Chernossolo Argilúvico, Gleissolo Melânico, Latossolo Amarelo, Neossolo Litólico, Neossolo Quartzarênico, Planossolo Háplico, Plintossolo Argilúvico, Plintossolo Pétrico, Vertissolo Ebânico. Os referidos solos possibilitaram o desenvolvimento de vegetação de grande porte (mapa plúvio-nebular), no platô do Planalto da Ibiapaba, mata seca na transição para as vertentes, caatinga arbórea e arbustiva nas áreas rebaixadas (SANTOS, 2019).

Esses elementos biofísicos criam condições que têm sido aproveitadas para o desenvolvimento das seguintes atividades: extração vegetal, com produção de fibras, ceras, madeira e oleaginosas; lavoura permanente, com cultivo de abacate, banana, café, castanha-de-caju, cocoda-baía, goiaba, laranja, limão, mamão, manga, maracujá, tangerina e urucum; lavoura temporária, associada ao cultivo de amendoim, arroz, batata-doce, cana-de-açúcar, fava, feijão, mandioca, melancia, milho, soja, tomate; pecuária, com destaque para a aquicultura, mel de abelha e criação de gado bovino, caprino, galináceo, ovino, suíno (IBGE, 2020).

\section{MATERIAIS E MÉTODOS}

O estudo compreende uma pesquisa aplicada, cujos procedimentos empregados geraram resultados que podem subsidiar o conhecimento da paisagem e a criação de estratégias conservação dos componentes ambientais. A pesquisa é explicativa, tendo em vista que se propôs a explicar as causas e consequência da possível degradação ambiental na Bacia do rio Piracuruca. $\mathrm{O}$ estudo empregou estatística para quantificação dos dados das componentes ambientais e construção do índice de degradação biofísica, fato que a torna uma pesquisa quantitativa.

Tomou-se como base a proposta metodológica de Oliveira (2011), que sofreu algumas alterações nos indicadores utilizados, a saber: a zonação climática cedeu lugar ao índice de aridez; os indicadores espessura e erosão do solo foram substituídos pela erodibilidade dos solos (k) e erosividade das chuvas; a estratificação e o percentual de ocupação da cobertura vegetal foram substituídos pelo índice de vegetação ajustado ao solo (SAVI).

Para a avaliação da degradação ambiental da Bacia do rio Piracuruca foi necessária a aquisição de arquivos alfanuméricos, vetoriais e matriciais, em banco de dados de órgãos governamentais. A seguir serão mais bem detalhados os procedimentos para identificação das áreas 
absolutas e relativas para cada indicador e índice biofísico. Ressalta-se, ainda, que se utilizou o Sistema de Informação Geográfica (SIG) $Q G I S$, versão 2.14, para montagem e manuseio do banco de dados e integração dos referidos indicadores.

\subsection{Indicadores biofísicos}

Para avaliação da degradação ambiental na Bacia do rio Piracuruca foi necessária a aquisição de arquivos alfanuméricos, matriciais e vetoriais, junto diversos órgãos governamentais. De posse dessas informações foi possível montar banco de dados que foi manuseado em Sistema de Informação Geográfica e, posteriormente, aplicação de álgebra de mapas e obtenção de produto final, ou seja, o mapa do índice biofísico de degradação ambiental. Desse modo, os indicadores utilizados serão mais bem detalhados a seguir.

\subsubsection{Geologia (Litotipos) - IBFD1}

Por meio do bioindicador litotipos (L) foi possível reconhecer o grau de resistência das rochas aos processos de intemperismo, conforme sugere a proposta metodológica de Oliveira (2011). Dessa forma, quanto menor a resistência das rochas menor resistência ofereceram à atuação dos agentes naturais, ou seja, mais intenso será o processo de morfogênese.

Para tal finalidade demandou-se a aquisição do arquivo vetorial da geodiversidade do estado do Ceará e do Piauí, no banco de dados do Serviço Geológico do Brasil (CPRM, 2006a; 2006b), em escala: 1.000.000. Associado a esses arquivos foi empregado, também, o RADAMBRASIL (BRASIL, 1973), para conhecimento da geologia e análise da litológica da área estudada.

\subsubsection{Geomorfologia (declividade média do relevo) - IBFD2}

A declividade média do relevo (Dm) está relacionada ao nível de inclinação da superfície. Fato que torna essencial o seu emprego, posto que permita conhecer as áreas de menor/maior inclinação, possibilitando indicar aquelas mais próprias ao desenvolvimento de atividades humanas e outras que devem ser preservadas, em observação ao Código Florestal, Lei $\mathrm{n}^{0}$ 12.651/2012 (BRASIL, 2012).

Para conhecimento da declividade média do relevo foram adquiridas imagens dos Modelos Digitais de Elevação (MDEs), da Missão Topográfica Radar Shuttle (SRTM), junto ao Serviço Geológico dos Estados Unidos (USGS, 2017a). Ao passo que para delimitação dos intervalos de declividade baseou-se nas classes propostas pelo Sistema brasileiro de classificação de solos (EMBRAPA, 2009). 
3.1.3. Clima (índice de aridez) - IBFD3

O bioindicador climático utilizado foi o índice de aridez (Ia), proposto por Thornthwaite (1941) e aperfeiçoado por Penman (1953), considerando o quociente entre a precipitação média anual e a evapotranspiração potencial média anual, conforme está expresso na equação 1.

$$
\mathrm{Ia}=\frac{\mathrm{P}}{\mathrm{Etp}}
$$

Onde:

Ia = Índice de aridez;

$\mathrm{P}=$ Pluviometria anual média;

Etp $=$ Evapotranspiração potencial anual média.

Para realização do índice de aridez demandou-se aquisição de dados de precipitação de 14 postos pluviométricos (Figura 1), considerando a série histórica de 1985 a 2016. Esses dados foram refinados por meio do pacote de programas computacionais USUAIS, conforme sugerem Oliveira e Sales (2016), cujas falhas foram corrigidas por meio da técnica de ponderação regional proposto por Tucci (1993). Posteriormente, foi possível efetivar a delimitar os intervalos de aridez, de acordo com a metodologia de Santos (2019).

\subsubsection{Solos (erosividade das chuvas) - IBFD4}

O indicador erosividade das chuvas $(\mathrm{R})$ está relacionado, de acordo com Back e Poleto (2018), ao potencial da energia cinética para promover desagregação do solo e, consequente, carregamento das partículas via escoamento superficial. Para conhecer o fator $\mathrm{R}$ foi utilizada técnica de regressão linear, que se baseia entre o índice médio mensal de erosão e o coeficiente de chuva, conforme equação 2, proposta por Lombardi Neto e Moldenhauer (1992).

$$
\mathrm{E}=67,355\left(\mathrm{r}^{2} / \mathrm{P}\right)^{0,85}
$$

Onde: $\mathrm{E}=$ média mensal do índice de erosão $(\mathrm{t} / \mathrm{ha} \cdot \mathrm{mm} / \mathrm{h}) ; \mathrm{r}=$ precipitação média mensal em mm; P = precipitação média anual em mm.

Para realização da análise do fator $\mathrm{R}$ foram utilizados os dados da série histórica de precipitação dos postos mencionados (Figura 1), anteriormente, ou seja, de 1985 a 2016. Posteriormente, ao refinamento dos dados, foi possível realização procedimento de delimitação das classes de Erosividade. 
3.1.5. Solos (erodibilidade dos solos) - IBFD5

A outra variável utilizada para análise dos solos foi a erodibilidade dos solos $(\mathrm{k})$. $\mathrm{O}$ fator $\mathrm{k}$ está associado, conforme atestam Wischmeier e Smith (1978), à suscetibilidade do solo a processos erosivos, bem como desprendimento e transporte pelos agentes de erosão.

Para conhecimento do fator $\mathrm{k}$ foi necessária a aquisição do arquivo vetorial dos solos da folha SB.24 - Jaguaribe, junto ao banco de dados da Infraestrutura Nacional de Dados Espaciais (INDE, 2014). Por sua vez, foi empregada a metodologia proposta por Crepani et al., (2001), que considera o grau de maturidade dos solos para sua classificação em relação à suscetibilidade frente os processo erosivos.

\subsubsection{Cobertura vegetal (índice de vegetação ajustado ao solo - SAVI) - IBFD6}

O bioindicador utilizado para análise da cobertura vegetal foi o índice de vegetação ajustado ao solo (SAVI), de tal modo, que foi necessária a aquisição de imagens do satélite Landsat 8 OLI, junto ao banco de dados do Serviço Geológico dos Estados Unidos (USGS, 2017b).

As imagens possuem resolução espacial de $30 \mathrm{~m}$ e as seguintes características: órbita/ponto 219/62 e 219/63 e data de passagem de 08/08/2016; órbita/ponto 218/63 e data de passagem de 01/08/2016. Nessas imagens foram executados procedimentos para obtenção da reflectância aparente e correção atmosférica.

Posteriormente, a realização desses procedimentos foi executada a aplicação da equação 3 , referente ao índice de vegetação ajustado ao solo (SAVI). Esse índice considera os efeitos do solo exposto nas imagens selecionadas, a partir do ajuste do índice de vegetação da diferença normalizada (NDVI), quando a superfície não está totalmente coberta pela vegetação (BORATTO; GOMIDE, 2013).

$$
\mathrm{SAVI}=\frac{(\mathrm{NIR}-\mathrm{R})}{(\mathrm{NIR}+\mathrm{R}+\mathrm{L})} *(1+\mathrm{L})
$$

Onde:

SAVI = Índice de vegetação ajustado ao solo;

NIR = Fluxo radiante no infravermelho próximo;

$\mathrm{R}=$ Fluxo radiante na região do vermelho visível;

$\mathrm{L}=$ Fator de ajuste do índice SAVI, que nesse estudo assumiu o valor de 0,5 , que é aplicado à vegetação com densidade intermediária.

A partir do produto obtido por meio da aplicação da equação 3, do SAVI, foi possível a realização da delimitação das classes de fisionomia da cobertura vegetal para a área pesquisada. 
3.1.7. Índice biofísico de degradação ambiental

De posse dos produtos referentes às seis variáveis descritas, acima, foi possível agrupa-los e produzir o índice biofísico de degradação ambiental para as unidades de paisagem da Bacia Hidrográfica do rio Piracuruca, conforme classificações apresentadas na tabela 3.

Ressalta-se que, a partir de adaptações à proposta metodológica de Oliveira (2011), foi realizado o cálculo da média aritmética da classe predominante em cada indicador dentro de cada unidade de paisagem da Bacia do rio Piracuruca. Os intervalos e classes do índice biofísico de degradação ambiental estão expostos na Tabela 2.

Tabela 2: Classes e intervalos do índice biofísico de degradação ambiental proposto para as unidades de paisagem da Bacia Hidrográfica do rio Piracuruca.

\begin{tabular}{cc}
\hline Classes & Intervalos \\
\hline Muito baixo & $4,00-5,00$ \\
Baixo & $3,00-4,00$ \\
Média & $2,00-3,00$ \\
Alta & $1,00-2,00$ \\
Muito alta & $0,00-1,00$ \\
\hline
\end{tabular}

Fonte: Oliveira (2011). Adaptado por Santos e Aquino (2017).

Cabe salientar que o valor 1 de cada indicador corresponde ao menor estágio de conservação, ao passo que o valor 4 ou 5 corresponde ao melhor estado de conservação ambiental da bacia pesquisada. Destaca-se que a estatística descritiva (média, variância, desvio padrão e coeficiente de variação) foi executada no software BioEstat, versão 5.3.

Tabela 3: Indicadores biofísicos propostos para avaliação da degradação ambiental da Bacia Hidrográfica do rio Piracuruca.

\begin{tabular}{|c|c|c|}
\hline Geologia (Litotipos ${ }^{1}$ ) - IBFD1 & Faixa & V.I. \\
\hline Basaltos, diabásios & - & (4) \\
\hline Arenitos, folhelho e siltito & - & $(3)$ \\
\hline $\begin{array}{l}\text { Arenito, conglomerado suportado por matriz, folhelho, } \\
\text { siltito arenoso }\end{array}$ & - & $(2)$ \\
\hline Areia, argila, cascalho & - & (1) \\
\hline Geomorfologia (Declividade $^{2}$ ) - IBFD2 & Faixa & V.I. \\
\hline Plano & 0 a 3 (Muito alta) & (5) \\
\hline Suave Ondulado & 3 a 8 (Alta) & (4) \\
\hline Ondulado & 8 a 20 (Média) & (3) \\
\hline Forte Ondulado & 20 a 45 (Baixa) & (2) \\
\hline Montanhoso & 45 a 75 (Muito baixa) & (1) \\
\hline Clima (Índice de aridez ${ }^{3}$ ) - IBFD3 & Faixa & V.I. \\
\hline Muito baixa & 1,64 a 1,90 & (5) \\
\hline Baixa & 1,38 a 1,64 & (4) \\
\hline Média & 1,12 a 1,38 & (3) \\
\hline Alta & 0,86 a 1,12 & (2) \\
\hline Muito alta & 0,60 a 0,86 & $(1)$ \\
\hline Solos (Fator R - Erosividade ${ }^{4}$ ) - IBFD4 & Faixa & V.I. \\
\hline
\end{tabular}




\begin{tabular}{|c|c|c|}
\hline ISSN 2318-2962 & \multicolumn{2}{|c|}{ Caderno de Geografia, v.31, n.65, 2021} \\
\hline Muito baixa & 6162,4 a 6795,8 & $(5)$ \\
\hline Baixa & 6795,9 a 7429,3 & $(4)$ \\
\hline Média & 7429,4 a 8062,7 & (3) \\
\hline Alta & 8062,8 a 8696,2 & $(2)$ \\
\hline Muito alta & 8696,3 a 9329,6 & $(1)$ \\
\hline Solos (Fator k - Erodibilidade ${ }^{5}$ - IBFD5 & Faixa & V.I. \\
\hline Latossolos, Argissolos & - & (4) \\
\hline Chernossolos, Planossolos & - & (3) \\
\hline Gleissolos, Plintossolos e Vertissolos & - & $(2)$ \\
\hline Neossolos & - & (1) \\
\hline Cobertura Vegetal $\left(\mathrm{SAVI}^{3}\right)$ - IBFD6 & Faixa & V.I \\
\hline Vegetação com alta atividade fotossintética & 0,6 a 0,8 (Muito alta) & $(5)$ \\
\hline Vegetação com média atividade fotossintética & 0,4 a 0,6 (Alta) & $(4)$ \\
\hline Vegetação com baixa atividade fotossintética & 0,2 a 0,4 (Média) & (3) \\
\hline $\begin{array}{l}\text { Área urbana/Vegetação com muito baixa atividade } \\
\text { fotossintética }\end{array}$ & 0,1 a 0,2 (Baixa) & (2) \\
\hline Solo exposto & 0 a 0,1 (Muito baixa) & (1) \\
\hline
\end{tabular}

Legenda: ${ }^{1}$ Adaptado de Oliveira (2011); ${ }^{2}$ Conforme estabelece o Sistema brasileiro de classificação de solos (EMBRAPA, 2009); ${ }^{3}$ De acordo com Santos (2019); ${ }^{4}$ Elaborado pelo autor (2020); ${ }^{5}$ Adaptado da proposta de Crepani et al., (2001).

Fonte: Adaptado pelo autor (2020).

\subsection{Mapeamento das unidades de paisagem}

Para mapeamento ambiental da Bacia do rio Piracuruca tomou-se como base as unidades de paisagem como categoria de análise. As unidades de paisagem, de acordo com Amorim e Oliveira (2008), apresentam interação entre os atributos do sistema natural e humano, fato que permite a identificação dos elementos responsáveis pela dinâmica da paisagem.

Esse mapeamento das unidades de paisagem é compatível com escala de 1:100.000 e partiu do uso do MDE SRTM, notadamente das cotas altimétricas e das classes de declividade do relevo. Tal base de mapeamento foi articulada às formações geológicas, rede de drenagem, associações de solos, fisionomia da cobertura vegetal e uso da terra. Posteriormente, ao mapeamento inicial foi executada atividade de campo nos meses de dezembro de 2017 e janeiro de 2018, cujo objetivo foi refinar o mapa de unidades de paisagem.

\section{RESULTADOS E DISCUSSÃO}

A seguir será realizada caracterização das unidades de paisagem mapeadas e, posterior, análise do índice de degradação ambiental para cada unidade da Bacia Hidrográfica do rio Piracuruca.

\subsection{Unidades de paisagem da Bacia do rio Piracuruca}

Foram mapeadas 10 unidades de paisagem na área da Bacia do rio Piracuruca (Figura 2), quais sejam: platô do Planalto da Ibiapaba, rebordos erosivos parcialmente dissecados do Planalto 
da Ibiapaba, rebordos erosivos moderadamente dissecados do Planalto da Ibiapaba, rebordos erosivos fortemente dissecados do Planalto da Ibiapaba, depressão monoclinal dissecada, depressão aplainada conservada, interflúvios tabulares, morros e colinas, fundos de vales associados à área de inundação, planícies fluviais.

Em seguida serão detalhadas cada uma das unidades de paisagem mapeadas, onde dar-se-á ênfase a caracterização e apresentação das potencialidades e limitações ao uso humano.

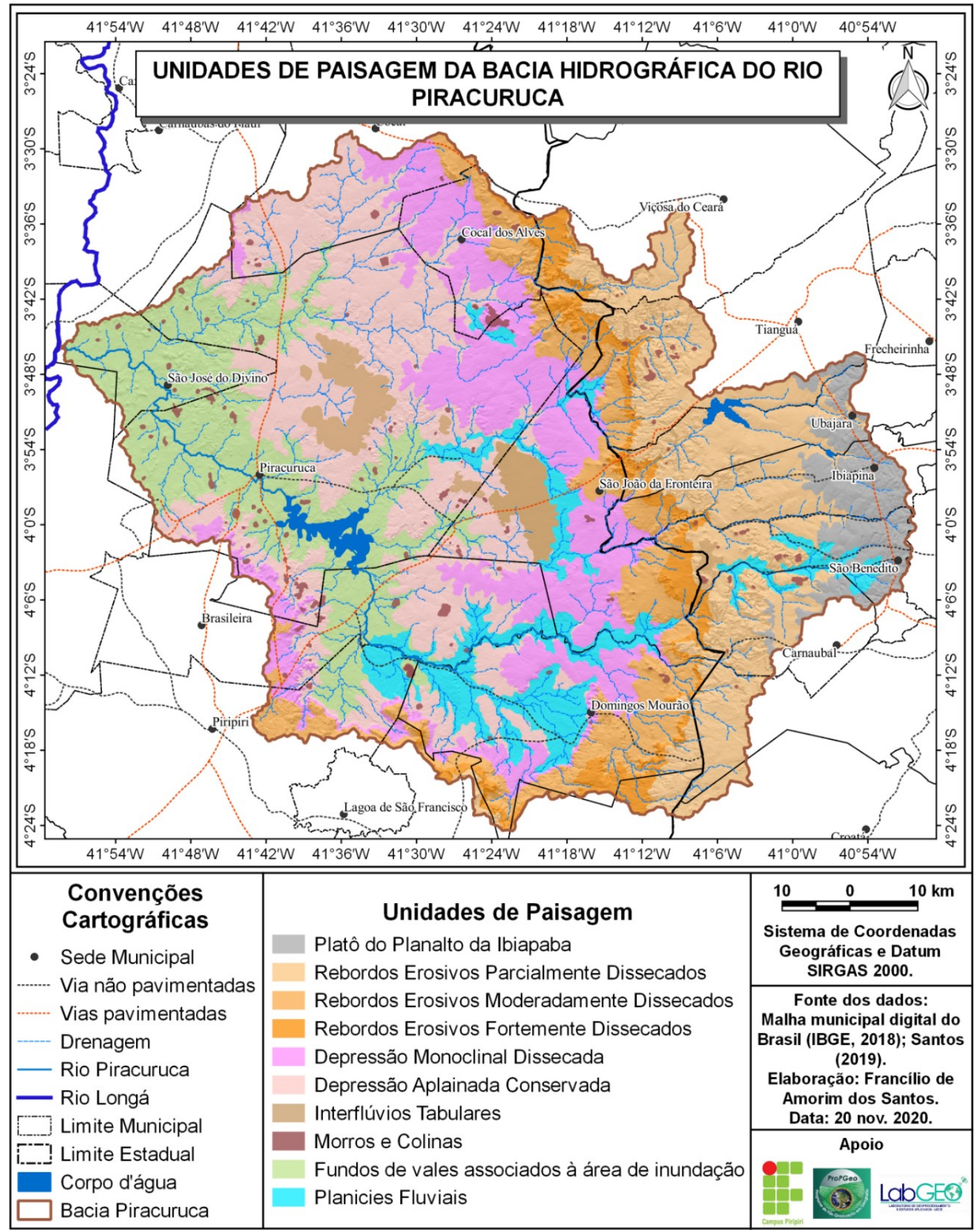

Figura 2 - Unidades de paisagem da Bacia Hidrográfica do rio Piracuruca.

Fonte: Santos (2019). 
4.1.1. Platô do Planalto da Ibiapaba

Ligado ao topo do Planalto da Ibiapaba, o platô abrange uma área de 4,5\% (349,7 $\left.\mathrm{km}^{2}\right)$, cuja composição está associada aos arenitos do Grupo Serra Grande (CPRM, 2006a), com predomínio de superfície com relevo plano a suave ondulado, em altitude que varia de 825 a $965 \mathrm{~m}$. Essa unidade exibe condições climáticas mais amenas, particularmente por apresentar elevados totais de precipitação, baixos níveis de perca de água por evapotranspiração e elevado excedente hídrico.

O solo encontrado nessa unidade diz respeito ao Latossolo Amarelo (INDE, 2014), que é recoberto por caatinga arbórea e mata plúvio-nebular. No platô são realizados cultivos temporários, a exemplo da cana-de-açúcar, e permanentes, como a bananicultura, além da prática da pecuária extensiva. Na unidade estão presentes áreas de nascentes e dos olhos d'água perenes, consideradas áreas de preservação permanente (APPs), pelo Código Florestal (BRASIL, 2012).

\subsubsection{Rebordos erosivos parcialmente dissecados do Planalto da Ibiapaba}

A unidade vem imediatamente posterior ao platô do Planalto, com decaimento topográfico em direção ao estado do Piauí. A unidade estende-se por $16,4 \%\left(1.263,7 \mathrm{~km}^{2}\right)$ da bacia pesquisada, estando assentada sobre os arenitos do Grupo Serra Grande (CPRM, 2006a), em cotas altimétricas de 505 a 825 m e superfície plana a suave ondulada no topo e ondulada a forte ondulada nas bordas.

Essa unidade destaca-se pela presença do açude Jaburu I, recurso hídrico de grande importância para o desenvolvimento econômico dos municípios situados no Planalto da Ibiapaba. $\mathrm{Na}$ referida unidade ocorrem totais pluviométricos e excedentes hídricos significativos. Ao passo que os solos identificados foram (INDE, 2014): Gleissolos, Latossolos e Neossolos. Esses são recobertos por caatinga arbustiva associada à vegetação herbácea. O açude Jaburu I possibilita o desenvolvimento, principalmente, da fruticultura e cultivos temporários, como da cana-de-açúcar. Contudo, ocorrem áreas que devem ser preservadas, devido apresentarem declividades superiores a $25^{\circ}$, outras se situam no entorno do açude Jaburu I e há, ainda, aquelas áreas de nascentes e margens dos cursos fluviais.

\subsubsection{Rebordos erosivos moderadamente dissecados do Planalto da Ibiapaba}

A unidade está em contato direto com a depressão monoclinal, estendendo-se por $9,1 \%$ $\left(702,1 \mathrm{~km}^{2}\right)$ da bacia pesquisada, situada sobre os arenitos da Formação Cabeças e Pimenteiras e Grupo Serra Grande (CPRM, 2006a). As cotas altimétricas da unidade variam de 185 a $425 \mathrm{~m}$ e predomínio de relevo plano a forte ondulado. 
Os níveis de precipitação, ainda, são significativos, os valores de evapotranspiração começam a aumentar mais significativamente e ocorre déficit hídrico. Nessa unidade têm-se os seguintes tipos de solos (INDE, 2014): Argissolos, Latossolos, Neossolos e Plintossolos. Os referidos solos são recobertos por caatinga arbustiva aberta. Nessa unidade já foram instalados equipamentos para aproveitamento dos ventos e produção de energia elétrica. Entretanto, a presença de nascentes e relevo íngreme demanda preservação, conforme aponta o Código Florestal (BRASIL, 2012).

\subsubsection{Rebordos erosivos fortemente dissecados do Planalto da Ibiapaba}

A unidade ocupa 4,4\% $\left(337,5 \mathrm{~km}^{2}\right)$ da área da bacia e está assentada sobre os arenitos da Formação Cabeças e Grupo Serra Grande (CPRM, 2006a; 2006b), o relevo apresenta níveis altimetria de 345 a $585 \mathrm{~m}$ e superfície bastante íngreme, com declividade variando de suave ondulada a montanhosa.

Os níveis de precipitação, ainda, são elevados indo de 960 a 1.460 mm anuais médios, com evapotranspiração elevada e predomínio de excedente. Na unidade em questão, além de rocha exposta, têm-se a ocorrência de Neossolo (INDE, 2014), que está recoberto por caatinga arbustiva aberta. Destaca-se, embora, haja potencial para instalação de parques eólicos, a presença de declividade elevada e diversas nascentes do rio Piracuruca, consideradas áreas de preservação permanente, sugere que essas áreas devam ser protegidas.

\subsubsection{Depressão monoclinal dissecada}

A unidade abrange $15,1 \%\left(1.161,8 \mathrm{~km}^{2}\right)$ da área da Bacia do rio Piracuruca, abrangendo os arenitos do Grupo Serra Grande e das Formações Pimenteiras e Cabeças (CPRM, 2006a; 2006b). O relevo possui cotas altimétricas entre 105 a $265 \mathrm{~m}$ e declividade plana a forte ondulada.

Os totais de chuva são significativos, há grande perda de água por evapotranspiração e predomina o déficit hídrico. No que diz respeito aos solos da área ocorrem os Argissolos, Neossolos e Plintossolos (INDE, 2014), com cobertura vegetal do tipo caatinga arbustiva densa, caatinga aberta e carrasco. A unidade potencial para aproveitamento geoturístico, particularmente pela presença de relevo ruiniforme, com destaque para o Parque Nacional de Sete Cidades (PN7C).

\subsubsection{Depressão aplainada conservada}

Ocupa 22\% (1.691,7 $\left.\mathrm{km}^{2}\right)$ da Bacia estudada, é uma extensa superfície aplainada que se estende sobre os depósitos colúvio-eluviais e os arenitos, folhelhos e siltitos das Formações 
Cabeças, Pimenteiras e Serra Grande (CPRM, 2006b). O relevo exibe altimetria que varia de 105 a $185 \mathrm{~m}$ e relevo plano a suave ondulado.

Nível de precipitação da área, ainda, apresenta significativos totais, a evapotranspiração é elevada e prevalece e déficit hídrico. O processo de formação dos solos resultou em: Argissolos, Latossolos, Neossolos, Planossolos e Plintossolos (INDE, 2014). Ao passo que a vegetação arbustiva densa recobre os solos encontrados na área. As características ambientais têm sido a base para o desenvolvimento de lavoura temporária, de milho e soja, e pecuária extensiva.

\subsubsection{Interflúvios tabulares}

Os interflúvios ocorrem por 2,9\% $\left(221,1 \mathrm{~km}^{2}\right)$ da Bacia do rio Piracuruca, são elevações residuais que separam vários rios da referida Bacia. A unidade está localizada sobre os depósitos sedimentares do Neógeno e dos arenitos originados das Formações Cabeças, Pimenteiras e Grupo Serra Grande (CPRM, 2006b). O relevo possui altitudes que variam de 105 a $185 \mathrm{~m}$ e declividades que oscilam entre plano a suave ondulado.

As condições climáticas apontam totais pluviométricos significativos para área, porém, há grande perca de água via evapotranspiração e prevalência de excedente hídrico. Os solos presentes na área são (INDE, 2014): Argissolos, Neossolos e Plintossolos. Esses configuram substrato para desenvolvimento de caatinga arbustiva aberta à densa. Nesse ambiente pratica-se a pecuária extensiva. Por outro lado, a presença de topos de morros com altura mínima de $100 \mathrm{~m}$ e inclinação média maior que $25^{\circ}$ configuram áreas de proteção permanente (BRASIL, 2012).

\subsubsection{Morros e colinas}

Essa unidade distribui-se por toda a Bacia pesquisada e ocupa $0,7 \%\left(55,2 \mathrm{~km}^{2}\right)$ de sua área. A litologia é constituída por arenitos, folhelhos e siltito das formações de natureza sedimentar. Os locais onde ocorrem os morros e colinas situam-se entre 25 a $825 \mathrm{~m}$ e declividades com variação entre suave ondulado a forte ondulado.

Apresentam grande variação pluviométrica indo de 860 a $1.460 \mathrm{~mm}$ médios anuais, evapotranspiração elevada e equilíbrio entre excedente e déficit hídrico. Ocorrem na unidade os Chernossolos, Gleissolos, Latossolos, Neossolos, Planossolos Plintossolos e Vertissolos (INDE, 2014), que são recobertos por caatinga arbustiva aberta ou densa. Por apresentar, em sua maioria, aspecto ruiniforme cria-se a possibilidade para aproveitamento geoturístico, devendo-se observar as limitações sugeridas pelo Código Florestal (BRASIL, 2012), ao limitar a exploração dos topos de morros com altura mínima de $100 \mathrm{~m}$ e inclinação média maior que $25^{\circ}$. 
4.1.9. Fundos de vales associados à área de inundação sazonal

Os fundos de vales ocupam 16,3\% $\left(1.256,1 \mathrm{~km}^{2}\right)$ da área da Bacia e estão alicerçados sobre as Formações Sardinha, Pimenteiras e Cabeças (CPRM, 2006a). O relevo possui cotas altimétricas entre 25 a $185 \mathrm{~m}$ e seu relevo exibe declividade que varia de plana a suave ondulada.

Os totais pluviométricos ultrapassam $1.360 \mathrm{~mm}$ anuais, porém a perca de água via evapotranspiração chega a $1.643 \mathrm{~mm}$ e há predomínio de déficit hídrico. Nessa unidade situa-se a barragem de Piracuruca, importante obra que perenizou o rio de mesmo nome e possibilitou a diversificação das atividades econômicas.

Nessa unidade ocorrem os Argissolos, Chernossolos, Plintossolos, Neossolos e Vertissolos (INDE, 2014), que são recobertos por carnaubal e caatinga arbustiva aberta e densa. Devido à presença da barragem, desenvolvem-se cultivos agrícolas, principalmente fruticultura, além da pecuária e plantio de pastagem. Existe, ainda, a possibilidade de aproveitamento geoturístico a partir do relevo ruiniforme. Entretanto, é necessário atentar-se para probabilidade de episódios de inundações próximas aos cursos fluviais no período chuvoso.

\subsubsection{Planícies fluviais}

Fruto do acúmulo de sedimentos, as planícies fluviais distribuem-se por $8,6 \%\left(665 \mathrm{~km}^{2}\right)$ da área pesquisada. A unidade em questão está situada sobre os arenitos das Formações Pimenteiras e Grupo Serra Grande (CPRM, 2006a; 2006b), particularmente nos fundos dos vales dos rios Jacareí, Catarina, Arabé e São Francisco. O relevo possui altitudes que variam de 25 a 185 m e 585 a 905 m, com declividade plana a suave ondulada.

As condições climáticas são diversificadas, com totais pluviométricos podendo chegar a $1.560 \mathrm{~mm}$ anuais, a perda de água por evapotranspiração pode atingir $1.503 \mathrm{~mm}$ anuais, enquanto o excedente e déficit apresentam relativo equilíbrio. Esses ambientes estão ligados à presença de Planossolos (INDE, 2014), que são recobertos por caatinga arbustiva aberta ou densa. Nas áreas mais secas é praticada a pecuária, enquanto nas áreas mais úmidas ocorrem cultivos temporários, a exemplo da cana-de-açúcar.

\subsection{Indicadores biofísicos e índice de degradação ambiental}

\subsubsection{Indicadores biofísicos}

A Figura 3 apresenta a distribuição percentual dos indicadores biofísicos utilizados no estudo, para a Bacia do rio Piracuruca. Dessa forma, observa-se a predominância de baixa resistência, frequente em 58,8\% da área da Bacia (Figura 3A), que está associado aos arenitos, conglomerados suportados por matriz, folhelhos e siltitos arenosos, que compreendem a formação Cabeças e o Grupo Serra 
Grande (CPRM, 2006a; 2006b). Fato que se justifica, de acordo com Penteado (1983) e BRASIL (1973), pela constituição arenítica e espessura média e o grosseira, planos de diaclasamento e estratificação, que de certo modo fragilizam as rochas frente os processo erosivos. A segunda classe mais representativa foi a média resistência, que ocorre por $23,7 \%$ da área estuda, e que está associada aos arenitos, folhelho e siltito dos depósitos colúvio-eluviais, que segundo (CPRM, 200b), compreendem sedimentos arenosos, areno-argilosos e conglomeráticos.

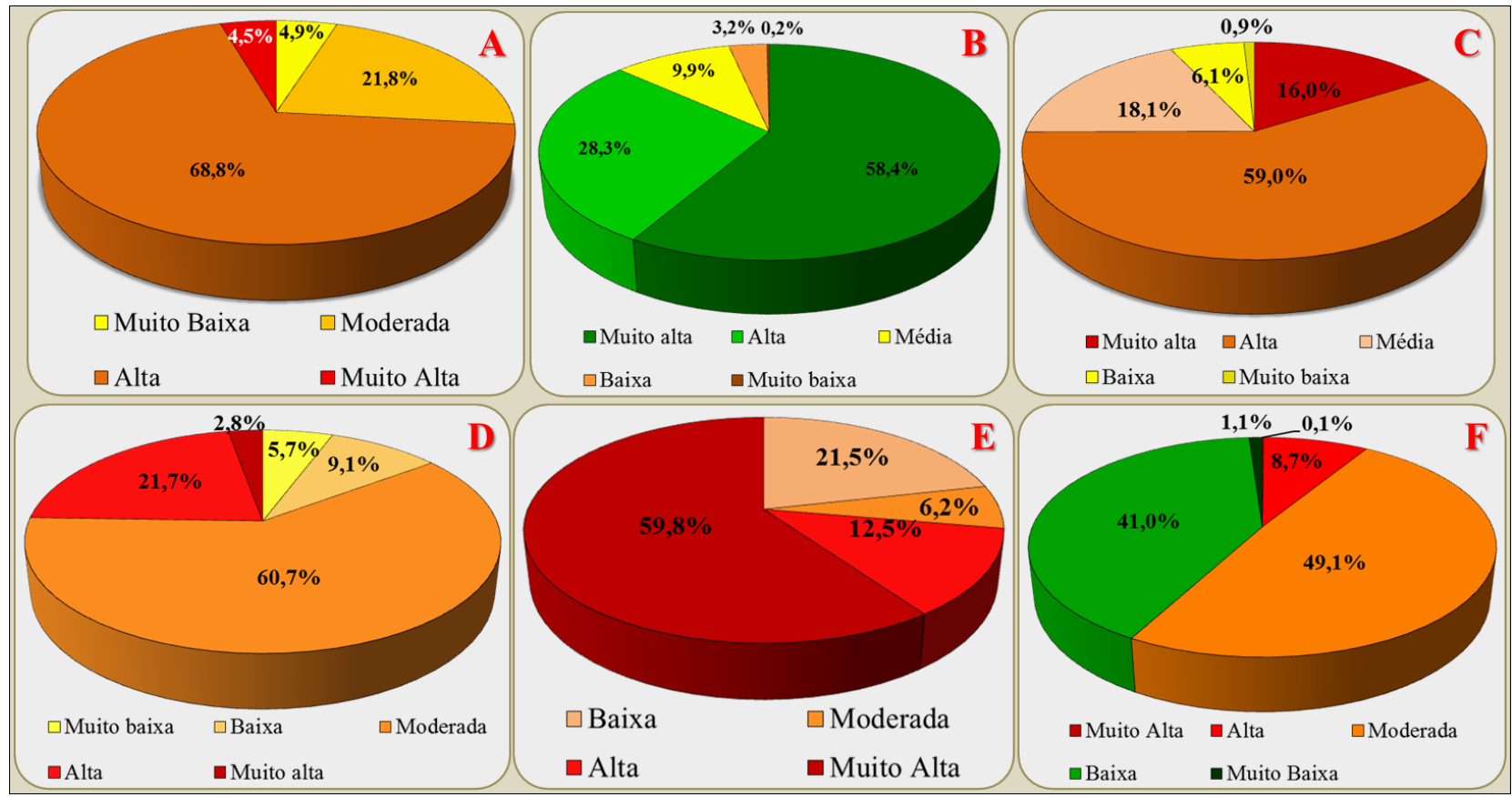

Figura 3 - Indicadores biofísicos de degradação ambiental utilizados no estudo.

Legenda: A: Litotipos (L)/resistência das rochas; B: Declividade média do relevo (Dm); C: Índice de aridez (Ia); D: Erosividade das chuvas (R); E: Erodibilidade dos solos (K); F: Índice de vegetação ajustado ao solo (SAVI).

Fonte: Santos (2019).

Pode-se observar que predomina na Bacia relevo com declividade plana (0 a 3\%), que ocorre por $58,4 \%$ da área, a essa classe segue-se a de declividade suave ondulada ( 3 a $8 \%$ ), identificada em 28,3\% (Figura 3B). Destaca-se, também, que em 0,2\% da Bacia pesquisada ocorre relevo montanhoso (45 a 75\%), com diversas nascentes do rio Piracuruca, fato que aponta necessidade de preservação por área de preservação permanente, segundo Código Florestal (BRASIL, 2012).

Os níveis de aridez na Bacia do rio Piracuruca estão relacionados à proximidade do Planalto da Ibiapaba, ou seja, o topo é mais úmido, ao passo que as áreas rebaixadas exibem maior rigor climático. $\mathrm{Na}$ Bacia prevalece a classe de aridez alta, cuja ocorrência dá-se por $59 \%$ de sua área, seguida da classe média e classe muito alta que são frequentes em 18,1\% e 16\%, respectivamente (Figura 3C).

A Figura 3D apresenta os dados relacionados ao fator R, onde se observa a preponderância da classe de erosividade moderada, identificada em 60,7\% da Bacia do rio Piracuruca, seguida pela classe de erosividade alta, cuja frequência deu-se por $21,7 \%$ da área estudada. Salienta-se que os 
resultados encontrados para o fator $\mathrm{R}$ estão associados aos maiores totais pluviométricos, principalmente no topo do Planalto da Ibiapaba, ou seja, vê-se a influência do relevo no condicionamento de umidade e, ainda, de maior erosividade.

Os tipos de solos identificados na Bacia do rio Piracuruca possibilitaram estimar os níveis de erodibilidade, conforme se observa na Figura 3E. Nessa visualiza-se a preponderância de erodibilidade muito alta, ocorrendo por $59,8 \%$ da área estudada, e que está ligada à ocorrência dos Neossolos (INDE, 2014), pois este tipo de solos caracteriza-se por ser pouco desenvolvido, mal drenado e de fácil desprendimento. A segunda classe mais representativa foi a de erodibilidade baixa, frequente em 21,5\% da Bacia pesquisada, e que diz respeito à presença dos Latossolos e Argissolos (INDE, 2014), que por serem mais desenvolvidos, ter maior profundidade, melhor drenagem em relação aos demais e localizarem-se em áreas planas apresentam menor suscetibilidade.

A cobertura vegetal na Bacia do rio Piracuruca sofre influência direta dos demais fatores ambientais, particularmente da pluviometria, tipos de solos e relevo. Dessa forma, conforme está exposto na Figura 3F, foi identificado que na Bacia predominância o tipo de vegetação com baixa atividade fotossintética, ocorrendo por $49 \%$ da área pesquisada, estando associada à catinga arbustiva. A essa classe segue-se a vegetação com atividade fotossintética média, que se estende por 40,9\% da Bacia, e diz respeito, particularmente, ao cerrado e à caatinga arbórea.

\subsection{2. Índice de degradação ambiental}

Na tabela 4 estão expostos a média e as medidas de dispersão dos indicadores biofísicos, que quando integrados resultaram no índice biofísico de degradação ambiental para as dez unidade de paisagem da Bacia do rio Piracuruca.

Por meio da tabela acima, pode-se observar que o indicador que se manteve mais estável foi o IBFD4, que apresentou variância de 0,2, fato relativo ao predomínio de média erosividade das chuvas. O IBFD6 foi o segundo com menor variância, apresentando valor de 0,3, que pode ser associado ao predomínio da vegetação de baixa a média atividade fotossintética. O IBFD1, que diz respeito à resistência das rochas, apresentou variância de 0,4 , fato justificado pela predominância de litologia arenítica na área estudada, principalmente os arenitos do Grupo Serra Grande. Por outro lado, o IBFD5 foi aquele que exibiu maior variância, com 1,7, principalmente pela presença de solos com muito alto potencial de erodibilidade, notadamente os Neossolos, considerados solos jovens e pouco desenvolvidos. 
Tabela 4: Indicadores biofísicos de degradação ambiental das unidades de paisagem mapeadas, média e medidas de dispersão (variância, desvio padrão e coeficiente de variação).

\begin{tabular}{|c|c|c|c|c|c|c|c|}
\hline \multirow{2}{*}{ Unidades de paisagem } & \multicolumn{7}{|c|}{ Indicadores biofísicos de degradação } \\
\hline & IBFD1 & IBFD2 & IBFD3 & IBFD4 & IBFD5 & IBFD6 & IBFD \\
\hline Platô do Planalto da Ibiapaba & 1 & 5 & 4 & 2 & 4 & 4 & 3,3 \\
\hline $\begin{array}{l}\text { Rebordos erosivos parcialmente } \\
\text { dissercados do Planalto da Ibiapaba }\end{array}$ & 1 & 5 & 3 & 2 & 1 & 3 & 2,5 \\
\hline $\begin{array}{l}\text { Rebordos erosivos moderadamente } \\
\text { dissercados do Planalto da Ibiapaba }\end{array}$ & 1 & 3 & 2 & 3 & 1 & 3 & 2,2 \\
\hline $\begin{array}{l}\text { Rebordos erosivos fortemente dissercados } \\
\text { do Planalto da Ibiapaba }\end{array}$ & 1 & 3 & 3 & 2 & 1 & 3 & 2,2 \\
\hline Depressão monoclinal dissecada & 1 & 5 & 2 & 3 & 1 & 3 & 2,5 \\
\hline Depressão aplainada conservada & 3 & 5 & 2 & 3 & 4 & 4 & 3,5 \\
\hline Interflúvios tabulares & 1 & 5 & 2 & 3 & 1 & 4 & 2,7 \\
\hline Morros e colinas & 1 & 3 & 2 & 3 & 1 & 4 & 2,3 \\
\hline $\begin{array}{l}\text { Fundos de vales associados à área de } \\
\text { inundação }\end{array}$ & 1 & 5 & 1 & 3 & 1 & 4 & 2,5 \\
\hline Planícies fluviais & 1 & 5 & 2 & 3 & 3 & 3 & 2,8 \\
\hline Média & 1,2 & 4,4 & 2,3 & 2,7 & 1,8 & 3,5 & 2,65 \\
\hline Variância & 0,4 & 0,9 & 0,7 & 0,2 & 1,7 & 0,3 & 0,2 \\
\hline Desvio padrão & 0,6 & 1,0 & 0,8 & 0,5 & 1,3 & 0,5 & 0,4 \\
\hline Coef. de variação (\%) & $52,7 \%$ & $22,0 \%$ & $35,8 \%$ & $17,9 \%$ & $73,1 \%$ & $15,1 \%$ & $16,7 \%$ \\
\hline
\end{tabular}

Fonte: Oliveira (2011). Adaptado por Santos e Aquino (2016).

Os desvios padrões apresentaram-se pouco variáveis, onde se pode destacar o IBFD5 e IBFD2, respectivamente, com valor de 1,3 e 1,0. Por sua vez, os coeficientes de variação demonstraram dispersão distinta, pois o IBFD5 (73,1\%), IBFD1 (52,7\%) e IBFD3 (35,8\%) tiveram dispersão alta e bastante heterogênea, enquanto o IBFD2 (22,0\%), IBFD4 (17,9\%) e IBFD5 $(15,1 \%)$ exibiram valores com média dispersão.

Desse modo, quando integrados os indicadores biofísicos foi possível observar que predomina, em geral, na Bacia do rio Piracuruca degradação biofísica média, variância média, desvio padrão pouco variável e média dispersão. Contudo, quando analisados de forma individual a depressão aplainada conservada $(3,5)$ e o platô do Planalto da Ibiapaba $(3,3)$ sobressaem-se como as unidades de paisagem que apresentam baixa degradação ambiental, enquanto todas as demais unidades classificam-se como tendo média degradação ambiental.

Os resultados desse estudo assemelham-se relativamente aos das pesquisas de Oliveira (2011), que apontaram o predomínio das unidades classificadas como de média degradação biofísica à desertificação, e de Santos et al., (2017), que sugerem que o Parque Nacional de Sete Cidades possui índice biofísico de degradação moderado. Por outro lado, a pesquisa apresenta-se diferente dos resultados encontrados por Santos e Aquino (2017), cujo estudo indicou preponderância de índice biofísico à desertificação muito baixo para todas as unidades geoambientais mapeadas nos municípios de Castelo do Piauí e Juazeiro do Piauí. 


\section{CONCLUSÕES}

O estudo atingiu seu objetivo, pois foi possível analisar o estado de degradação ambiental das unidades de paisagem da Bacia do rio Piracuruca, a partir de indicadores biofísicos. Desse modo, cabe destacar que a foram mapeadas as seguintes unidades de paisagem na Bacia do rio Piracuruca: platô do Planalto da Ibiapaba, rebordos erosivos parcialmente dissercados do Planalto da Ibiapaba, rebordos erosivos moderadamente dissercados do Planalto da Ibiapaba, rebordos erosivos fortemente dissercados do Planalto da Ibiapaba, depressão monoclinal dissecada, depressão aplainada conservada, interflúvios tabulares, morros e colinas, fundos de vales associados à área de inundação, planícies fluviais.

A análise das condições ambientais da Bacia, de modo geral, demonstrou predominância de: rochas com baixa resistência, que ocorre em $58,8 \%$ da área; relevo com declividade plana, distribuída por 58,4\%; aridez alta, com ocorrência em $59 \%$ da área; erosividade das chuvas moderada, que se estende por $60,7 \%$; erodibilidade dos solos muito alta, identificada por $59,8 \%$ da área; vegetação com baixa atividade fotossintética, frequente em $49 \%$ da área estudada.

A metodologia proposta para análise da degradação ambiental, que considerou seis indicadores biofísicos, das dez unidades de paisagem da referida bacia possibilitou reconhecer que: o indicador mais estável foi o IBFD4, com variância de 0,2 , relativo à ocorrência de média erosividade das chuvas, ao passo que o IBFD5 exibiu a maior variância, com 1,7, justificado pela presença de solos jovens e pouco desenvolvidos; o indicador IBFD5 foi aquele que apresentou maior desvio padrão, com 1,3; enquanto IBFD5, foi o que demonstrou maior dispersão, tendo apresentado coeficiente de variação de $73,1 \%$.

A integração dos valores dos seis indicadores apontou que, de modo geral, prevalece na Bacia do rio Piracuruca degradação biofísica média, variância média, desvio padrão pouco variável e média dispersão. Por outro lado, a depressão aplainada conservada e o platô do Planalto da Ibiapaba diferem das demais unidades de paisagem por terem exibido baixa degradação ambiental, enquanto as outras oito unidades apresentaram degradação ambiental média.

Diante do que foi apresentado no estudo pode-se inferir que as dez unidades de paisagem mapeadas exibem diversas potencialidades, a exemplo do seu relevo plano, significativos totais pluviométricos, solos bem desenvolvidos, afloramentos rochosos, entre outros. Esses elementos podem ser utilizados para desenvolvimento de agricultura, pecuária e roteiros turísticos. Ao passo que as rochas com baixa resistência, relevo montanhoso, os solos jovens, alta erosividade e erodibilidade e alta aridez podem ser um limitador às atividades humanas.

Os valores encontrados para os indicadores e o índice biofísico de degradação indicam possibilidades para tomada de decisão, particularmente em relação ao desenvolvimento das atividades humanas, além da possibilidade de criação e implementação de políticas públicas para 
recuperação de áreas degradadas e conservação e/ou preservação daquelas áreas que apresentam limitações ao uso.

\section{REFERÊNCIAS}

AGÊNCIA NACIONAL DE ÁGUAS. Hidro Web - Sistema de Informações Hidrológicas. Séries históricas: ano de 1985 a 2016. Disponível em: <http://hidroweb.ana.gov.br/>. Acesso em: $11 \mathrm{fev}$. 2017.

AMORIM, R. R.; OLIVEIRA, R. C. As unidades de paisagem como uma categoria de análise geográfica: o exemplo do município de São Vicente - SP. Sociedade \& Natureza, n. 20, p. 177198,2008

AQUINO, C. M. S.; OLIVEIRA, J. G. B. Avaliação de indicadores biofísicos de degradação/desertificação no núcleo de São Raimundo Nonato, Piauí, Brasil. Revista Equador, v. 1, n. 1, p. 44-59, 2012.

BACK, A. J.; POLETO, C. Distribuição espacial e temporal da erosividade das chuvas no estado de Santa Catarina, Brasil. Revista Brasileira de Climatologia, v. 22, p. 381-403, 2018.

BORATTO, I. M. P.; GOMIDE, R. L. Aplicação dos índices de vegetação NDVI, SAVI e IAF na caracterização da cobertura vegetativa da região Norte de Minas Gerais. In: SIMPÓSIO BRASILEIRO DE SENSORIAMENTO REMOTO, 16., 2013, Foz do Iguaçu. Anais... Foz do Iguaçu: SBSR, 2013, p. 7345-7352.

BRASIL. Mapas estaduais de geodiversidade: Ceará. Rio de Janeiro: CPRM. 2006a. Documento cartográfico em arquivo vetorial. Disponível em $<$ http://geobank.sa.cprm.gov.br $>$. Acesso em: 17 nov. 2020 .

Mapas estaduais de geodiversidade: Piauí. Rio de Janeiro: CPRM. 2006b. Documento cartográfico em arquivo vetorial. Disponível em $<$ http://geobank.sa.cprm.gov.br $>$. Acesso em: 17 nov. 2020.

BRASIL. Ministério de Minas e Energias. Departamento Nacional de Produção Mineral. Projeto RADAM: levantamento dos recursos naturais, v.02, Folha SB. 23 / 24 - Teresina / Jaguaribe; geologia, geomorfologia, solos, vegetação e uso potencial da terra. Rio de Janeiro, 1973.

BRASIL. Novo Código Florestal. Lei no 12.651, de 25 de maio de 2012. Dispõe sobre a proteção da vegetação nativa; altera as Leis $\mathrm{n}^{\mathrm{o}} \mathrm{s}$ 6.938, de 31 de agosto de 1981, 9.393, de 19 de dezembro de 1996, e 11.428, de 22 de dezembro de 2006; revoga as Lei $\mathrm{n}^{\circ} \mathrm{s} 4.771$, de 15 de setembro de 1965, e 7.754, de 14 de abril de 1989, e a Medida Provisória no 2.166- 67, de 24 de agosto de 2001; e dá outras providências. 2012.

CAMARGO, L. H. R. A Geoestratégia da Natureza: a Geografia da Complexidade e a Resistência à possível Mudança do Padrão Ambiental Planetário. Rio de Janeiro: Bertrand Brasil, 2012. 240p.

CAZULA, L. P.; MIRANDOLA, P. H. Bacia Hidrográfica - conceitos e importância como unidade de planejamento: um exemplo aplicado na bacia hidrográfica do Ribeirão Lajeado/SP - Brasil.

Revista Eletrônica da Associação dos Geógrafos Brasileiros, Três Lagoas, v. 7, n. 12, p. 101124. 2010. 
CREPANI, E.; MEDEIROS, J. S.; HERNANDEZ FILHO, P.; FLORENZANO, T. G.; DUARTE, V.; BARBOSA, C. C. F. Sensoriamento Remoto e Geoprocessamento Aplicados ao Zoneamento Ecológico-Econômico e ao Ordenamento Territorial. São José dos Campos: INPE, 2001. 109p.

EMBRAPA - Centro Nacional de Pesquisa de Solos. Sistema brasileiro de classificação de solos. Rio de Janeiro: EMBRAPA-SPI, 2009. 355p.

FLORENZANO, T. G. Geotecnologias na geografia aplicada: difusão e acesso. Revista do Departamento de Geografia, v. 17, p. 24-29. 2005.

INSTITUTO BRASILEIRO DE GEOGRAFIA E ESTATÍSTICA. Malha municipal digital do Brasil: situação em 2018. Rio de Janeiro: IBGE, 2014. Disponível em: <ftp://geoftp.ibge.gov.br/malhas_digitais/>. Acesso em: 04 dez. 2019.

Cidades. 2020. Disponível em: <https://cidades.ibge.gov.br/>. Acesso em: 01 jun. 2020.

Manual Técnico de Geomorfologia. Coordenação de Recursos Naturais e Estudos Ambientais. 2. ed. Rio de Janeiro: IBGE, 2009. 175p.

INFRAESTRUTURA NACIONAL DE DADOS ESPECIAIS. Mapa de Solos da Folha SB.24: Jaguaribe. Disponível em: <http://www.visualizador.inde.gov.br/>. 2014. Acesso em: 13 set. 2018.

LOMBARDI NETO, F.; MOLDENHAUER, W. C. Erosividade da chuva: sua distribuição e relação com perdas de solos em Campinas - SP. Bragantina, Campinas, v. 51, n. 2, p. 189-1996, 1992.

NEVES, C. E.; MACHADO, G.; HIRATA, C. A.; STIPP, N. A. F. A importância dos geossistemas na pesquisa geográfica: uma análise a partir da correlação com o ecossistema. Soc. \& Nat., Uberlândia, v. 26, n. 2. p. 271-285, 2014.

OLIVEIRA, J. G. B.; SALES, M. C. L. Usuais: programas para uso em análise ambiental. Revista Equador, Teresina, v. 5, n. 2, p. 36-60, 2016.

OLIVEIRA, V. P. V. Indicadores biofísicos de desertificação, Cabo Verde/África. Revista Mercator, Fortaleza, v. 10, n. 22, p. 147-168, 2011.

PENMAN, H. L. The Physical Bases of Irrigation Control. In: INTERNATIONAL HORTICULTURAL CONGRESS. 13., 1953. Proceedings... 1953. p. 1-13.

PFALTZGRAFF, P. A. S.; TORRES, F. S. M.; BRANDÃO, R. L. (Org.). Geodiversidade do estado do Piaui. Recife: CPRM, 2010. 260p.

ROSS, J. L. S. Geomorfologia: ambiente e planejamento. 8. ed. São Paulo: Contexto, 2010. 85p.

SANTOS, F. A. Resiliência ambiental a secas e a inundações na Sub-bacia Hidrográfica do rio Piracuruca (CE-PI). 2019. 268 f. Tese (Doutorado em Geografia) - Universidade Estadual do Ceará, Fortaleza, 2019.

SANTOS, F. A.; AQUINO, C. M. S. Indicadores biofísicos em área suscetível à desertificação no Meio-Norte do Piauí: o caso dos municípios de Castelo do Piauí e Juazeiro do Piauí. In: ROCHA, 
G. C.; SAnTOS, F. A.; AQUINO, C. M. S. Piauí do Litoral ao Meio-Norte: gestão, uso e conservação. Teresina: EDUFPI, 2017.

SANTOS, F. A.; PACIÊNCIA, L. G. M.; MENDES, J. M.; AQUINO, C. M. S. Indicadores biofísicos de degradação ambiental no Parque Nacional de Sete Cidades, Nordeste do Brasil. Revista de Geociência do Nordeste, v. 2, p. 670-680, 2016.

SANTOS, L. P. S.; WEBER, L. S. O Geoprocessamento como ferramenta para construção de um modelo para compensação financeira pela preservação ambiental. Revista Percurso, Maringá, v. 5, n. 2, p. 19-46, 2013.

SERVIÇO GEOLÓGICO DO BRASIL. Mapas estaduais de geodiversidade: Ceará. Rio de Janeiro: CPRM. 2006a. Documento cartográfico em arquivo vetorial. Disponível em: $<$ http://geobank.sa.cprm.gov.br>. Acesso em: 14 jan. 2014.

. Mapas estaduais de geodiversidade: Piauí. Rio de Janeiro: CPRM. 2006b. Documento cartográfico em arquivo vetorial. Disponível em: $<$ http://geobank.sa.cprm.gov.br $>$. Acesso em: 14 jan. 2014.

ThORNTHWAITE, C. W. Atlas of Climatic Types in the United States. Miscell Publ. n.421. U.S. Departament of Agricultures, Forest Service, 1941.

THORNTHWAITE, C. W.; MATHER, J. R. The Water Balance - Publications in Climatology. New Jersey: Centerton, v. 8, n. 1, 1955.

TEIXEIRA, A. H. C.; LEIVA, J. F.; PACHECO, E. P.; GARÇON, E. A. M. Monitoramento de indicadores biofísicos no Submédio São Francisco com aplicação de geotecnologias. In: SIMPÓSIO DE RECURSOS HÍDRICOS DO NORDESTE, 14., 2018, Maceió. Anais... Maceió: 2018, p. 1-10.

TUCCI, C. E. M. Hidrologia: ciência e aplicação. Porto Alegre: Eds. da UFRGS, 1993. 944p.

UNITED STATES GEOLOGICAL SERVICE (Serviço Geológico dos Estados Unidos). Digital elevation: SRTM 1 Arc-Second Global. 2017. Disponível em: <http://earthexplorer.usgs.gov/>. Acesso em: 23 nov. 2017a. 23 nov. 2017 b.

Collection: landsat archive. Disponível em: <http://earthexplorer.usgs.gov/>. Acesso em:

WISCHMEIER, W. H.; SMITH, D. D. Predicting rainfall erosion losses: a guide to conservation planning. Washington: USDA, 1978. 58p. 